\title{
Sexual health promotion programme: Participants' perspectives on capacity building
}

Health Education Journal

$1-14$

(C) The Author(s) 2014

Reprints and permissions: sagepub.co.uk/journalsPermissions.nav DOI: I0.II77/00।78969|4563320 hej.sagepub.com

@SAGE

\author{
Brian Keogh, Louise Daly, Danika Sharek, \\ Jan De Vries, Edward McCann and Agnes Higgins \\ School of Nursing and Midwifery, Trinity College Dublin, Dublin, Ireland
}

\begin{abstract}
Objectives: The aim of this study was to evaluate a Health Service Executive (HSE) Foundation Programme in Sexual Health Promotion (FPSHP) with a specific emphasis on capacity building.

Design: A mixed-method design using both quantitative and qualitative methods was used to collect the data. Setting: The FPSHP was delivered to staff working in health, education and community settings and was designed and facilitated by sexual health promotion staff who are part of the Irish HSE.

Methods: A survey, designed by the researchers, as well as individual telephone interviews with past participants was used to evaluate the programme. Out of a possible 200 participants, 97 completed the questionnaire (response rate $49 \%$ ), and a total of 22 telephone interviews were completed.

Results: There was generally a high level of satisfaction with the FPSHP. Participants reported high levels of individual and intra-organisational capacity-building activities, but apart from networking, interorganisational capacity-building activities were reported less frequently and tended to be ad hoc in nature. Satisfaction with the programme was high and so was the perception of its sustained impact. Motivation, satisfaction with the programme and attending of further training were strong predictors of reported sustained impact.

Conclusion: Capacity building in sexual health promotion was affected positively by participation in the programme. Nonetheless, a greater emphasis on capacity building at an inter-organisational level needs to be considered. It is recommended that participants need to be motivated, guided and supported in the use of strategies to achieve this.
\end{abstract}

\section{Keywords}

Capacity building, evaluation, Ireland, mixed methods, sexual health promotion

\section{Corresponding author:}

Brian Keogh, School of Nursing and Midwifery, Trinity College Dublin, 24 D’Olier Street, Dublin 2, Ireland.

Email: keoghbj@tcd.ie 


\section{Introduction}

Internationally, there is a growing recognition of the importance of promoting all aspects of health, including sexual health. Concerns have been raised around the need for developing sustainable sexual health promotion efforts with an emphasis on capacity building as a primary aim (Barry, 2008). In line with this development, this article highlights the capacity-building impact of the Foundation Programme in Sexual Health Promotion (FPSHP) in the Republic of Ireland. This programme was developed to enhance the sexual health promotion capacity of a variety of professionals, including health, education and community workers. Capacity building has been defined as 'an approach to the development of sustainable skills, organisational structures, resources and commitment to health improvement in health and other sectors to prolong and multiply health gains many times over' (Hawe et al., 1999, cited by New South Wales Health Department, 2001: i). The findings presented here draw from a larger study which evaluated the FPSHP from multiple perspectives (Higgins et al., 2013). Considering the dearth of published international empirical work specifically evaluating capacity-building outcomes of these types of programmes, there is a need for these kind of studies.

\section{Background}

Sexual health promotion is a global concern with recognised public health benefits and has been defined by the Department of Health (2003) in England as 'Any activity which proactively and positively supports the sexual and emotional health and well-being of individuals, groups, communities and the wider public and reduces the risk of HIV transmission' (p. 8). The World Health Organization (WHO) $(2003,2010)$ calls for a multi-sectoral, multilevel approach to the promotion of sexual health planning and service delivery with individuals, groups and communities across five key domains: law, policy and human rights; society and culture; education; health systems; and economics. Therefore, to be effective, sexual health promotion must address the needs of vulnerable and marginalised groups, draw on rights-based and life-course approaches and demonstrate cultural, religious and situation-based appropriateness by being cognisant of how related considerations affect sexual health beliefs and practices (Department of Health, Social Services and Public Safety [DHSSPS], 2008; Higgins et al., 2009; Scottish Executive, 2005; WHO, 2010).

Sexual health promotion tends to be delivered by a range of personnel working across multiple sectors and by a wide variety of agencies. However, it is acknowledged that preparation for the role is often inadequate (Kong et al., 2009; McCann, 2010). This implies that a satisfactory direction for sexual health promotion practice and competencies could be lacking for those involved in its delivery (Department of Health, 2003). Therefore, one of the primary concerns in building health promotion capacity is how to train people so that they are prepared and skilled to engage with health promotion (Barry, 2008). Health promotion workers operate first to reduce risk factors or risk conditions and second, at the level of the health promotion delivery system, to build capacity and maintain programmes of health promotion (Hawe et al., 1997, 2008). Related work can involve three dimensions: health infrastructure or service development; programme maintenance or sustainability; and building problem-solving capability of organisations and communities (Hawe et al., 2008; New South Wales Health Department, 2001). It is suggested that extending health promotion capacity-building beyond health contexts contains the potential to 'build individual skills, strengthen community action and empower organisations to promote sustainable health behaviours and support healthy environments' (VicHealth, 2012a: 1). As such, to sustain health promotion, it is vital that the workforce is developed to have competence in the formulation and implementation of both health promotion policy and practice and that education and training is 
Table I. Overview of content.

Introduction to the programme

Sexual health promotion in the Irish context

Sexual health: A life-course approach

Physical sexual health (contraception and STIs)

Self-esteem and sexual health

Sex, society and culture

Irish law and sexual health

Power and sex

Policy development

Facilitation skills

STI: sexually transmitted infection.

ongoing so that personnel are responsive to today's dynamic health, social and political situations (Barry, 2008). Sexual health promotion workers also need to be comfortable with their own sexuality and possess the confidence to engage with sexual health-related issues in an open and relaxed way (Allen, 2009; Higgins et al., 2009).

To achieve these ends, programmes of education and training for those with responsibility for delivering sexual health promotion need to increase participant knowledge; promote personal development; facilitate the exploration of values, attitudes and beliefs relating to sexual health and sexual practices; enable the acquisition of communication, teaching and facilitation skills and promote confidence in health promotion delivery (Ahmed et al., 2006; DHSSPS, 2008; MurphyLawless et al., 2008). Much of the available literature exploring preparation for sexual health promotion is health professional specific. This literature identifies the beneficial outcomes of education for those who promote and support sexual health in terms of enhanced practitioner knowledge, skills and comfort where single and inter-professional education and training occurs (Byrne et al., 2006; Fronek et al., 2011; Higgins et al., 2012; Simpson et al., 2006; Walker and Harrington, 2002). Some of this research indicates the need for longer or spaced out programmes to potentially enhance the depth of engagement and deepen comfort through greater dialogue around sexual issues (Fronek et al., 2011; Higgins et al., 2012). Outside of the health-care context, research from the education sector also demonstrates increases in confidence and comfort; however, knowledge of sexual health-related facts, difficulties with translation of knowledge and facilitation strategies can be challenging, with researchers suggesting that cultural context and differences require consideration (Ahmed et al., 2006). Researchers have also demonstrated the importance of ongoing support, including peer support for sexual health promoters (Ahmed et al., 2006; Wight and Buston, 2006).

\section{Overview of the programme}

The aim of the FPSHP is to enhance participants' confidence, comfort, knowledge and skills in relation to sexual health, thus increasing their capacity to incorporate sexual health promotion practices into their work. The FPSHP adopts a life-course approach which acknowledges that people are sexual beings from birth to death and have needs and wants in relation to their sexuality and its healthy expression which include but are not limited to those associated with sexual activity. The programme is delivered over five 2-day sessions and was developed and delivered by staff within the Health Promotion and Improvement, Health and Well Being Division of the Irish Health Service Executive (HSE). The programme content is outlined in Table 1. 
Throughout the programme, there is an emphasis on experiential learning with personal development and an awareness of the participant's own values and beliefs about sexuality and sexual health central to the approach. In line with the programme's strategy of capacity building, other elements such as a library service, follow-up education days, a biannual newsletter and ongoing support from the facilitators are implemented to support the participants following completion of the programme. In total, 200 participants completed the 12 programmes offered. Analyses of completion rates suggest these were very high with $93 \%$ of those starting the programme going on to complete it.

\section{Aims of the study}

The overall aim of the study was to evaluate the FPSHP with a specific emphasis on capacity building.

\section{Methods}

A mixed-methods design with both qualitative and quantitative approaches was used to examine the programme and participants' perceptions of their capacity-building practices. For the quantitative data, a 37-item questionnaire was designed by the research team. This was divided into five sections as follows:

\section{Section A: Biographical information.}

Section B: Experience of the impact of the programme on knowledge, skills, comfort and confidence and satisfaction with the programme.

Section C: Impact of the programme on capacity-building activities (individual, organisational and inter-organisational level).

Section D: Sustainability of the impact of the programme (factors that facilitated and hindered application and sustainability).

Section E: Overall views on the content of programme.

Participants' perceptions of their capacity-building abilities following the programme were measured in terms of levels of knowledge, comfort, confidence and motivation to engage in sexual health promotion activities. Satisfaction with the programme was also assessed. Sustainability factors that influenced the ability to build capacity and implement their learning from the programme were also identified. In addition, specific capacity-building indicators such as facilitating workshops and developing sexual health policy were also measured. The survey asked the participants to indicate what individual, organisational and community capacity-building activities they were involved in before and after the programme. For the qualitative data, individual semi-structured telephone interviews were conducted with a selection of the past participants. The main purpose of the interviews was to gain a deeper understanding of the participants' capacity-building experiences within their own practice, within their organisation and within the wider community following participation in the FPSHP.

\section{Reliability and validity}

The internal consistency of the 18 evaluative 11-point Likert Scales (Sections B, C and D) was high $($ Cronbach alpha =.92). The 11-point scales generated more variability than equivalent 4- or 5-point scales encountered in similar evaluative studies. The validity of an instrument designed for 
a single study cannot easily be established, but content validity was optimised by the use of validated measures as a model for the design of the questions. Furthermore, external validity was assisted by the high response rate (49\% of the programme participants returned the survey). The mixed-method design was used in order to allow a comparison between interview and survey responses. The high similarity between these two types of data supports the validity of both aspects of the study. Content validity was optimised by ensuring that all evaluative questions were reflective of the content, aims and objectives of the programme evaluated in this study.

\section{Sampling}

Anyone who had successfully completed the FPSHP up to the point of the evaluation was eligible to take part in the survey $(n=200)$. The survey was available to complete either online or in hardcopy formats. The programme facilitators acted as gatekeepers and distributed the survey to the participants' postal or email address depending on the contact information available. For the telephone interviews, participants were requested to self-select via an 'opt-in' form which was sent to them as part of the survey package or through a secure online link.

\section{Data analysis}

For the quantitative data, descriptive and inferential statistics were generated using the Statistical Package for Social Sciences (SPSS) version 20 (IBM Corp., 2011). Frequency distributions were generated for each item to establish whether the key objectives of the programme were achieved. Inferential methods (Analysis of Variance and Multiple Regression) were used to identify key factors and predictors of the main impact variables. To explore differences between groups, independent sample t-tests and Pearson chi-square tests were conducted as appropriate. The qualitative data from the interviews were audio-recorded and transcribed verbatim and subjected to a thematic analysis. Following an initial open coding of six transcripts, a coding framework was developed which assisted in the coding of the remaining transcripts. Once open coding was completed, the codes were examined for overlap and collapsed to form higher order themes and subthemes.

\section{Ethics}

Ethical approval was granted from the Research Ethics Committee of the Faculty of Health Sciences in Trinity College Dublin.

\section{Findings}

\section{Quantitative results}

All past participants were eligible for inclusion in the study $(n=200)$; however, only 197 could be contacted. A survey response rate of $49 \%$ was achieved $(n=97)$. The mean age of the participants was 42 years (standard deviation $[S D]=9.05$ years), and the majority were female $(92 \% n=89)$. The areas that the participants reported working in were child protection, counselling, psychotherapy, family support, residential care, rape crisis and social work. Analysis of participants who returned the survey against the overall population of people who completed the FPSHP indicated that they were representative in terms of gender and background, with some level of oversampling among participants who attended the follow-up training days. 
Table 2. Self-reported effects of the programme $(n=97)$.

\begin{tabular}{|c|c|c|}
\hline & Range (observed) & Mean $(S D)$ overall \\
\hline \multicolumn{3}{|c|}{ Knowledge, comfort and confidence variables: How did the programme affect your ...? } \\
\hline Knowledge of issues of sexual health $(n=97)$ & $1-10$ & $8.2(1.6)$ \\
\hline Comfort in relation to issues of sexual health $(n=97)$ & $2-10$ & $8.3(1.7)$ \\
\hline $\begin{array}{l}\text { Confidence in relation to issues of sexual health } \\
(n=97)\end{array}$ & $3-10$ & $8.4(1.5)$ \\
\hline $\begin{array}{l}\text { Motivation to engage with sexual health promotion } \\
\text { activities }(n=96)\end{array}$ & $3-10$ & $8.5(1.3)$ \\
\hline \multicolumn{3}{|l|}{ Skills variables: How did the programme affect your ...? } \\
\hline $\begin{array}{l}\text { Ability to develop policies around sexual health } \\
(n=92)\end{array}$ & $1-10$ & $6.6(2.1)$ \\
\hline $\begin{array}{l}\text { Problem-solving skills around sexual health issues } \\
(n=97)\end{array}$ & $1-10$ & $7.4(1.8)$ \\
\hline Facilitation skills around sexual health $(n=96)$ & $0-10$ & $7.9(2.0)$ \\
\hline Sexual health promotion skills $(n=97)$ & $1-10$ & $8.1(1.4)$ \\
\hline $\begin{array}{l}\text { Ability to communicate about issues of sexual health } \\
(n=97)\end{array}$ & $0-10$ & $8.3(1.9)$ \\
\hline \multicolumn{3}{|c|}{ Awareness and attitudes variables: How did the programme affect your ...? } \\
\hline $\begin{array}{l}\text { Self-awareness in relation to sexual health issues } \\
(n=97)\end{array}$ & $0-10$ & $8.2(2.0)$ \\
\hline $\begin{array}{l}\text { Understanding of your own values and attitudes } \\
\text { towards sexuality }(n=97)\end{array}$ & $0-10$ & $8.2(2.0)$ \\
\hline
\end{tabular}

SD: standard deviation.

Satisfaction with the programme. Participants were highly satisfied with the programme in terms of its content, delivery and their own learning with mean ratings on a $0-10$ Likert Scale between 8.5 and 9. The overall mean satisfaction was rated at $8.8(S D=1.3)$.

Capacity building. The participants were asked to rate the impact of the programme on several aspects of their sexual health promotion practice on a Likert scale ranging from 0 (not improved at all) to 10 (very greatly improved) (Table 2). Results were again singularly positive, and the majority of the mean ratings were between 8 and 8.5. Key variables associated with capacity building on an organisational level were somewhat lower, such as problem-solving skills around sexual health issues, $7.4(S D=1.8)$; ability to develop policies around sexual health, $6.6(S D=2.1)$ and facilitation skills around sexual health, $7.9(S D=2.0)$.

The participants were also asked to identify the sexual health promotion activities that they engaged in before and after attending the programme from a predetermined list. In the analysis of the findings, a comparison was made between those participants who had engaged in sexual health promotion activities both before and after the programme $(n=43)$. Overall, there was a doubling of sexual health promotion activities after the programme (Table 3). The modest increase in networking with other individual and organisations (40\%) did not produce a concomitant increase in other inter-organisational capacity-building activities.

Factors influencing sustainability. Participants were presented with two Likert scales ( 0 - not at all; 10 - to a very great extent) to report their perceptions of the degree to which the programme had a sustained impact at present on their sexual health promotion practices and their perception of their 
Table 3. Engagement in activities related to sexual health promotion.

\begin{tabular}{|c|c|c|c|}
\hline Practice $(n=43)$ & Before programme & After programme & Difference \\
\hline \multicolumn{4}{|l|}{ Individual capacity-building practices } \\
\hline $\begin{array}{l}\text { Attending training or education on sexual } \\
\text { health promotion (CPD) }\end{array}$ & $10(23 \%)$ & $23(53 \%)$ & $+13(30 \%)$ \\
\hline $\begin{array}{l}\text { Providing formal sexual health education } \\
\text { to clients or service users in a group } \\
\text { setting }\end{array}$ & 14 (33\%) & $24(56 \%)$ & $+10(23 \%)$ \\
\hline Referring people to sexual health services & $24(56 \%)$ & $33(77 \%)$ & $+9(19 \%)$ \\
\hline $\begin{array}{l}\text { Assessing sexual health promotion needs } \\
\text { of clients }\end{array}$ & $26(60 \%)$ & 33 (77\%) & $+7(17 \%)$ \\
\hline $\begin{array}{l}\text { Providing sexual health education to } \\
\text { clients or service users in a one-to-one } \\
\text { setting }\end{array}$ & $27(63 \%)$ & $33(77 \%)$ & $+7(14 \%)$ \\
\hline \multicolumn{4}{|l|}{ Organisational capacity-building practices } \\
\hline $\begin{array}{l}\text { Raising awareness of sexual health } \\
\text { promotion needs within your organisation }\end{array}$ & 14 (33\%) & $32(74 \%)$ & $+18(41 \%)$ \\
\hline $\begin{array}{l}\text { Providing formal sexual health education } \\
\text { to staff within your organisation }\end{array}$ & $\mathrm{I}(2 \%)$ & 14 (33\%) & $+13(31 \%)$ \\
\hline $\begin{array}{l}\text { Developing written information materials } \\
\text { related to sexual health }\end{array}$ & $4(9 \%)$ & $16(37 \%)$ & $+12(28 \%)$ \\
\hline $\begin{array}{l}\text { Developing sexual health services within } \\
\text { your organisation }\end{array}$ & $6(14 \%)$ & 17 (40\%) & $+11(26 \%)$ \\
\hline $\begin{array}{l}\text { Auditing sexual health promotion practices } \\
\text { within your organisation }\end{array}$ & $4(9 \%)$ & $12(28 \%)$ & $+8(19 \%)$ \\
\hline $\begin{array}{l}\text { Assessing sexual health promotion } \\
\text { education needs of staff within your } \\
\text { organisation }\end{array}$ & $5(12 \%)$ & $13(30 \%)$ & $+8(18 \%)$ \\
\hline $\begin{array}{l}\text { Developing sexual health policies/ } \\
\text { guidelines within your organisation }\end{array}$ & $5(12 \%)$ & $12(28 \%)$ & $+7(17 \%)$ \\
\hline Engaging in research on sexual health & $5(12 \%)$ & $13(30 \%)$ & $+8(18 \%)$ \\
\hline $\begin{array}{l}\text { Adapting administrative practice to } \\
\text { include sexual health items, for example, } \\
\text { developing/changing assessment forms to } \\
\text { include sexual health }\end{array}$ & $2(5 \%)$ & $7(16 \%)$ & $+5(11 \%)$ \\
\hline \multicolumn{4}{|l|}{ Inter-organisational capacity-building practices } \\
\hline $\begin{array}{l}\text { Networking about sexual health with } \\
\text { other individuals or organisations }\end{array}$ & $10(23 \%)$ & 27 (63\%) & $+17(40 \%)$ \\
\hline Publishing articles on sexual health & $2(5 \%)$ & $7(16 \%)$ & $+5(11 \%)$ \\
\hline $\begin{array}{l}\text { Developing sexual health policies/ } \\
\text { guidelines outside of your organisation }\end{array}$ & $0(0 \%)$ & $3(7 \%)$ & $+3(7 \%)$ \\
\hline $\begin{array}{l}\text { Providing formal sexual health education } \\
\text { to staff outside your organisation }\end{array}$ & $2(5 \%)$ & $5(12 \%)$ & $+3(7 \%)$ \\
\hline $\begin{array}{l}\text { Developing sexual health services outside } \\
\text { your organisation }\end{array}$ & I (2\%) & $3(7 \%)$ & $+2(5 \%)$ \\
\hline $\begin{array}{l}\text { Average number of activities reported per } \\
\text { person (mean/SD) and difference before/ } \\
\text { after }\end{array}$ & $3.77(2.60)$ & $7.60(3.99)$ & +3.83 \\
\hline
\end{tabular}

CPD: Continuous Professional Development; SD: standard deviation. 
ability to sustain that impact into the future. The response to the two questions was very similar, with mean scores ranging from 7.5 to 7.6: present impact (mean $(M)=7.6, S D=2.1$ ) and ability to sustain impact $(M=7.5, S D=1.8)$. These outcomes suggest that participants were very positive about their ability to sustain change after programme completion. The participants were also asked to indicate the factors that helped and hindered the implementation of their learning and practices following attendance at the FPSHP. The most helpful personal factors reported by the participants were increased confidence and knowledge and skills (97\%) and personal autonomy to implement change $(80 \%)$. Practical resources such as the availability of sexual health promotion materials $(98 \%)$ and human resources such as follow-up support from the programme facilitators (77\%) were also perceived as important in helping support sustainability. In terms of factors that hindered sustained change, lack of time (39\%), financial resources (38\%) and an unsupportive organisational culture $(23 \%)$ were seen as the most hindering factors.

Predicting sustainability. In order to determine which factors were most predictive of the perceived sustainable impact of the programme, a multiple regression analysis was performed in which all quantifiable variables (Likert scales/dichotomous variables) addressed in the survey were entered to estimate their potential as predictor of sustainable impact at present. This outcome variable was chosen as the most reliable reflection of sustainability in this study and suggests that several variables are significant predictors of the outcome variable. Levels of motivation, satisfaction with the programme and further training predicted $59 \%$ of the variation in perceived sustainability of the programme. In addition, five other factors, such as supportive organisational culture, engagement in sexual health promotion as part of my job, engagement in sexual health promotion as part of voluntary work, implementation hindered by lack of financial resources and engaging in research on sexual health after attending the programme, added another $30 \%$ to the explained variance.

Differences between sectors involved. Participants on the programme came from a variety of work sectors (health, education, youth work). To determine whether there were any significant differences in reported effects of the programme on participants' capacity-building practices, independent samples $t$-test were conducted. Participants in the health sector $(M=6.98, S D=2.17)$ reported a significantly lower impact of the programme on their problem-solving skills than those not in the health sector $(M=7.71, S D=1.24)(t[67.81]=2.00, p=.049)$. Similarly, the programme appeared to have lesser impact on those in the education sector in terms of knowledge, confidence and ability to communicate as compared to those not in the education sector.

- Knowledge $(t \quad[95]=2.21, p=.0290$ : education $(M=7.64, S D=2.04) /$ non-education $(M=8.43, S D=1.33)$.

- Confidence $(t[95]=2.67, p=.009)$ : education $(M=7.72, S D=1.90) /$ non-education $(M=8.61$, $S D=1.24)$.

- Ability to communicate $(t[26.56]=2.18, p=.039)$ : education $(M=7.28, S D=2.95) /$ noneducation $(M=8.60, S D=1.15)$.

To determine whether there were any significant differences in the sexual health promotion activities engaged in by each group before and after the programme, Pearson chi-square tests were conducted on those with cell counts greater than $20 \%$. While some minor differences were noted, no overall pattern emerged among the three levels of capacity-building practices across the groups. For example, a significantly greater proportion of people working within the health sector were providing sexual health education to clients/service users in a one-to-one setting before the programme compared to those not working within the health sector $\left(\chi^{2}[1, N=97]=4.152, p=.042\right.$ / $\mathrm{Phi}=.207$ ); and a significantly smaller proportion of people within the community sector were 
developing sexual health services within their organisation after the programme compared to those not working in the community sector $\left(\chi^{2}[1, N=97]=9.817, p=.002 / \mathrm{Phi}=-.318\right)$. However, given the minor variations and sample size, these results need to be interpreted with caution.

\section{Qualitative results}

A total of 22 telephone interviews were conducted with past participants with an emphasis on elaborating on their capacity-building activities. Of these, 4 participants were male and 18 were female. Their average age was 43.6 years (range 28-59 years.) Participants described themselves as working in health $(n=12)$, community $(n=6)$, the youth sector $(n=2)$ and education $(n=2)$. None of the participants were currently working time in the disability sector although two people reported doing some work in this area.

Three themes were identified from the analysis:

1. Building individual confidence and comfort with sexual health promotion.

2. Policy development and educational delivery.

3. Networking and educational initiatives within the community.

Similar to the quantitative data, the participants reported increased capacity-building activities at individual and organisational levels. At an individual level, participants reported increased confidence and motivation to include sexual health promotion activities within their roles. An increase in the participants' knowledge and comfort in this area also assisted this process. Organisational capacity-building initiatives were mainly centred on educating other staff and raising awareness of sexual health issues within the participants' immediate workplace. To a lesser extent, developing guidelines and policies was also reported.

There were fewer reports of inter-organisational capacity-building activities, and these tended to be more informal and $a d$ hoc in character. In terms of barriers to capacity building, similar to the survey findings, limited financial resources, lack of scope within organisations for capacity building and unsupportive management structures were seen as the major obstacles to sustaining capacity-building activities following attendance at the FPSHP. In terms of supporting sustainability, the FPSHP did incorporate a number of initiatives all of which were highlighted as particularly useful by those participants who reported using them. An overview of the qualitative findings is shown in Table 4.

\section{Discussion}

Sexual health promotion capacity-building requires a holistic, multifocal, multi-sectoral and interdisciplinary approach (WHO, 2010) that is underpinned by particular knowledge, skills and competencies. In terms of sexual health capacity building, the HSE FPSHP described here is an example of a programme that sets out to build sexual health capacity at the individual, organisational and inter-organisational levels among different stakeholder groups (health, education and social care). In the context of Hawe et al.'s (1997) three levels of capacity building, the overall conclusion of this research is that the programme is effective in terms of capacity building at a personal and an organisational level and to a lesser degree at an inter-organisational level.

\section{Building capacity}

A recognised indicator of capacity-building success is the enhancement of competence in health promotion activities (VicHealth, 2012b). The findings demonstrate that participants' 
Table 4. Overview of interview participants' capacity-building activities following FPSHP.

Theme Examples of capacity-building activities Illustrative example

Building individual confidence - Increased motivation, knowledge, 'My participation in the programme and comfort with sexual health comfort and confidence to talk promotion about issues of a sexual nature.

- Increased interest in pursuing further education. allowed me to discuss sexual matters with individuals directly; prior to the course I would have avoided the subject. Further, I

Policy development and educational delivery

Networking and educational initiatives within the community
- Incorporating principles into everyday working practices.

- Raising awareness about sexual health and sexual health promotion nine workshops since l've returned needs within organisation.

- Using facilitation skills.

- Conducting workshops/training with organisational staff.

- Conducting workshops/training with clients within organisation.

- Discussing sexual health concepts with staff.

- Developing guidelines.

- Developing new sexual health policy and changing existing policies within the organisation

- Writing articles for publication.

- Conducting sexual health workshops in other organisations.

- Providing sexual health promotion became aware of my personal discriminations and realised where these came from'

'I've conducted maybe eight or from the sexual health course. l've introduced it to our staff here, the staff team of twenty-three so I would have done one workshop a month at the start, half day a month at the start of every staff meeting' training to volunteers.

- Formal and informal networking with other individuals and organisations.

- Contributing to, and membership of, national committees involved in sexual health.

- Contributing to national policy formation.

- Doing research.

FPSHP: Foundation Programme in Sexual Health Promotion.

knowledge, confidence, comfort and skill increased and that they engaged in a wide variety of sexual health promotion activities following programme completion. These included policy development, participation in change, provision of education to staff and service users and communication around the topic of sexual health and sexual health promotion. These findings support previous research that demonstrates the benefits of education and training for healthcare practitioners involved in sexual health promotion (Byrne et al., 2006; Fronek et al., 2011; Higgins et al., 2012; Simpson et al., 2006; Walker and Harrington, 2002) and are consistent with the World Health Organization principle that multi-strategy activities are necessary to effective health promotion (Rootman, 2001). 
One of the expectations of individual competency development is the assumption that skills will transfer into the strengthening of community action across organisations (VicHealth, 2012b). While there was some evidence of networking and involvement in educational initiatives beyond participant organisations, the degree of inter-organisational capacity building reported was less; this suggests a potential need to enhance the focus on this in future programme delivery. Perhaps, establishing a plan for inter-organisational capacity building with support from facilitators could be a key outcome for future FPSHPs. The Hub and Spokes model which seems to be the dominant way of interacting with participants can be expanded with greater emphasis being placed on how the 'spokes' and their organisations can better communicate and collaborate (Bryan and O'Kelly, 1999; Rogers et al., 2009). In addition, exploring issues such as trust between organisations and developing communication and information sharing strategies that promote trust and mutual understanding may foster a greater sense of collaboration between organisations (Vangen and Huxham, 2003).

Of particular note is that the profile of FPSHP participants reflects the three priority settings identified for health promotion in the Republic of Ireland - health, education and community (HSE, 2011). While the Department of Health (2003) in England and others advocate for interdisciplinary training and development among health-care professionals and organisations involved in sexual health, research that explores the impact of sexual health promotion education programmes on non-health-care practitioners or incorporates health and non-health practitioners within the same educational programme is sparse. While a small number of participants were critical of the interdisciplinary mix in terms of knowledge differences, and some minor differences in quantitative findings were noted between groups, overall the findings from the evaluation suggest that sexual health capacity education can be approached from an interdisciplinary perspective, rather than a health discipline-specific viewpoint.

\section{Sustaining change}

Consistent with national strategy (HSE, 2011), the FPSHP also aimed to build sustainability beyond the duration of the programme. The building of sustainability is internationally recognised as of equal interest to that of capacity building for health promotion (New South Wales Health Department, 2001; Rootman, 2001). Indeed, O’Loughlin et al. (1998) highlight the necessity to plan for long-term sustainability of programmes, hence the importance of evaluating sustainability-related outcomes of health promotion initiatives. Within the literature, sustainability is generally aligned with programme continuance; however, for the purposes of this study, sustainability refers to participants' perceptions of their ability to sustain the programme learning and practices over time. The sustainability findings demonstrated that participants were confident in their ability to sustain their sexual health promotion activities after the programme and considered that there were more supports for, than obstacles to, sustaining change. The factors identified as statistically best predicting sustainability of change were participant motivation, overall satisfaction with the FPSHP and engaging in further training and education. To a lesser degree, having a supportive organisational environment, engagement in sexual health promotion as part of role, time and a lack of impediment due to financial constraints were also factors that sustained impact.

Within the qualitative data, participants reported the biannual newsletter and support from facilitators as important factors in enabling them to sustain change. These findings are consistent with factors identified in the wider literature. An important addition to the existing evidence base, added by the evaluation of the FPSHP, is the opportunity to engage in sexual health promotion as part of one's role. Indeed, building capacity in others and sustaining sexual health promotion activities was reported to be more difficult for participants who were not actively immersed within a sexual 
health-specific context or where sexual health promotion activities were not an explicit component of their role. As the ability of participants to sustain activities is an important consideration for those delivering the programme, accepting participants who lack opportunities to engage in sexual health promotion activities may be financially costly, a waste of effort for facilitators, and it may also be disheartening for the participants concerned (Swerisson, 2007).

Finally, while managers did provide some corroborating evidence that participants had indeed made changes within the organisation (Higgins et al., 2013) without a longitudinal study incorporating methodologies such as observation and evidence from service users, the impact of the programme on capacity-building outcomes is still tentative.

\section{Limitations}

This evaluation would have benefited from the use of a control group, a larger sample size and the use of pre- and post-test measures. In addition, the voluntary basis of participation may have led to a bias towards interested participants who had positive memories of the programme.

\section{Conclusion and recommendations}

Findings support the reach and impact of the programme participants' knowledge, confidence, skills and sexual health promotion activities. However, greater emphasis needs to be placed on the importance of developing inter-organisational capacity within the programme as well as providing participants with strategies for achieving this. This could be achieved by assisting participants to foster networks with other organisations and by providing support and guidance for inter-organisational activities such as ones outlined in Table 3. Furthermore, recruiting participants whose roles include sexual health promotion activities from the onset will help achieve a greater degree of sustainability. In addition, the findings indicate that sexual health capacity education can be approached from an interdisciplinary perspective, rather than a health-discipline-specific viewpoint.

In conclusion, in view of the limitations of this evaluation, and the absence of evaluations of similar programmes within the literature, consideration should be given to conducting a long-term evaluation of the capacity building and sustainability of the FPSHP to monitor effectiveness over time. In addition, more robust designs, such as a longitudinal pre-post study design or a randomised control trial, need to be considered. There is also a need to recruit a larger sample to determine whether there are significant differences in the sexual health promotion activities engaged in by each of the stakeholder groups involved.

\section{Declaration of conflicting interests}

The authors declare no conflict of interest.

\section{Funding}

This work was supported by funding from the Health Service Executive Crisis Pregnancy Programme, Ireland.

\section{References}

Ahmed N, Flisher AJ, Mathews C, et al. (2006) Process evaluation of the teacher training for an AIDS prevention programme. Health Education Research 21: 621-632.

Allen L (2009) 'It's not who they are it's what they are like': Re-conceptualising sexuality education's 'best educator' debate. Sex Education 9: 33-49. 
Barry M (2008) Capacity building for the future of health promotion. IUHPE: Promotion and Education XV: $56-58$.

Bryan D and O'Kelly M (1999) Hub-and-spoke networks in air transportation: An analytical review. Journal of Regional Science 39(2): 275-295.

Byrne A, Watson R, Butler C, et al. (2006) Increasing the confidence of nursing staff to address the sexual health needs of people living with HIV: The use of motivational interviewing. AIDS Care 18: 501-504.

Department of Health (2003) Effective Sexual Health Promotion. A Toolkit for Primary Care Trusts and Others Working in the Field of Promoting Good Sexual Health and HIV Prevention. London: Department of Health.

Department of Health, Social Services and Public Safety (DHSSPS) (2008) Sexual Health Promotion Strategy and Action Plan, 2008-2013. Belfast: DHSSPS.

Fronek P, Kendall M, Booth S, et al. (2011) A longitudinal study of sexuality training for the interdisciplinary rehabilitation team. Sexuality and Disability 29: 87-100.

Hawe P, King L, Noort M, et al. (2008) Working invisibly: Health workers talk about capacity-building in health promotion. Health Promotion International 13: 285-295.

Hawe P, Noort M, King L, et al. (1997) Multiplying health gains: The critical role of capacity-building within health promotion programs. Health Policy 39: 29-42.

Health Service Executive (HSE) (2011) The Health Promotion Strategic Framework. Dublin: HSE National Health Promotion Office.

Higgins A, Barker P and Begley CM (2009) Sexuality and mental health nursing in Ireland: Weaving the veil of socialised inhibition. Nurse Education Today 29(3): 357-364.

Higgins A, Daly L, de Vries J, et al. (2013) Capacity Building Impact of the Foundation Programme in Sexual Health Promotion: A Multiple Stakeholder Perspective. Dublin: School of Nursing and Midwifery, Trinity College Dublin.

Higgins A, Sharek D, Nolan M, et al. (2012) Mixed methods evaluation of an interdisciplinary sexuality education programme for staff working with people who have an acquired physical disability. Journal of Advanced Nursing 68: 2559-2569.

IBM Corp. (2011) IBM SPSS Statistics for Windows (version 20.0). Armonk, NY: IBM Corp.

Kong SKF, Wu LH and Loke AY (2009) Nursing students' knowledge, attitude and readiness to work for clients with sexual health concerns. Journal of Clinical Nursing 18: 2372-2382.

McCann E (2010) Investigating mental health service user views regarding sexual and relationship issues. Journal of Psychiatric and Mental Health Nursing 17(3): 251-259.

Murphy-Lawless J, Higgins A and Pembroke S (2008) Women in Sexuality Education. The Impact of the Irish Family Planning Association's WiSE UP Programme. Dublin: School of Nursing and Midwifery, Trinity College Dublin.

New South Wales Health Department (2001) A Framework for Building Capacity to Improve Health. Sydney, NSW, Australia: New South Wales Health Department.

O'Loughlin J, Renaud L, Sanchez Gomez L, et al. (1998) Correlates of the sustainability of community-based heart health promotion interventions. Preventive Medicine 27: 702-712.

Rogers H, Turner E, Thompson G, et al. (2009) Hub-and-spoke model for a 5-day structured patient education programme for people with Type 1 diabetes. Diabetic Medicine 26(9): 915-920.

Rootman I (2001) A framework for health promotion evaluation. In: Rootman I, Goodstadt M, Hyndman B, et al. (eds) Evaluation in Health Promotion (WHO Regional Publications European Series, no. 92). Geneva: WHO, pp. 3-6.

Scottish Executive (2005) Respect and Responsibility. Strategy and Action Plan for Improving Sexual Health. Edinburgh: Scottish Executive.

Simpson G, Anwar S, Wilson J, et al. (2006) Improving the rehabilitative management of client sexual health concerns after neurological disability: Evaluation of a staff sexuality training programme in New Zealand. Clinical Rehabilitation 20: 847-859.

Swerisson H (2007) Understanding the sustainability of health programs and organisational change. A Paper for the Victorian Quality Council, Faculty of Health Sciences, La Trobe University, Melbourne, VIC, Australia, June. 
Vangen S and Huxham C (2003) Nurturing collaborative relations: Building trust in inter-organizational collaboration. Journal of Applied Behavioral Science 39: 5-31.

VicHealth (2012a) Capacity Building for Health Promotion. Information Sheet. Carlton, VIC, Australia: Victorian Health Promotion Foundation.

VicHealth (2012b) Capacity Building for Health Promotion. Information Sheet. Levels of Capacity Building and Ways of Measuring Outcomes. Carlton, VIC, Australia: Victorian Health Promotion Foundation. Available at: http://www.vichealth.vic.gov.au/Publications/VicHealth-General-Publications/CapacityBuilding-for-Health-Promotion.aspx

Walker B and Harrington D (2002) Effect of staff training on staff knowledge and attitudes about sexuality. Educational Gerontology 28: 639-654.

Wight D and Buston K (2006) Meeting needs but not changing goals: Evaluation of in-service teacher training for sex education. Oxford Review of Education 29: 521-544.

World Health Organization (WHO) (2003) Progress in Reproductive Health Research: Sexual Health - A New Focus for WHO, issue 67. Geneva: WHO.

World Health Organization (WHO) (2010) Developing Sexual Health Programmes. A Framework for Action. Geneva: WHO. 